\title{
Gross and Morphometrical Studies on Scapula of Barking Deer (Muntiacus muntjak)
}

\author{
Jasvinder Singh Sasan , Kamal Sarma and Shalini Suri
}

Division of Veterinary Anatomy, F.V.Sc \& A.H, SKUAST-Jammu, R.S Pura-181102, India

*Corresponding author

\section{A B S T R A C T}

\begin{tabular}{|l|}
\hline K e y w o r d s \\
Barking deer, \\
Coracoid process, \\
Glenoid cavity, \\
Scapula, Sub-scapular \\
fossa
\end{tabular}

\section{Introduction}

The Indian muntjac (Muntiacus muntjak), also called red muntjac and barking deer, is a common muntjac deer species in South and Southeast Asia. It is listed as Least Concern on the IUCN (International Union for Conservation of Nature) Red List.

It has soft, short, brownish or greyish hair, sometimes with creamy markings. It gives calls similar to barking, usually upon sensing a predator (hence the common name for all muntjacs of "barking deer"). Muntjac is one of the smallest deer species and can be distinguished by its short antlers which only branch out to a few points, the visible canines of males, and perhaps most notably the large postorbital scent glands they use to mark their territory. They have played a major role in Southern Asia, being hunted for sport and for their meat and skin. Often, these animals are hunted around the outskirts of agricultural areas, as they are considered a nuisance for damaging crops and ripping bark from trees. In literature, abundant information is available on gross anatomy of scapula of domestic animals (Raghavan, 1964). Literature is also available on scapula of Blue bull (Bharti and Singh, 2017), chital (Choudhary et al., 2013) and blackbuck (Choudhary, 2015). Due to paucity of literature on the scapula of Indian barking deer, the present study has been planned. The outcome of this study will be 
useful to the field veterinarians, zoo veterinarians and wildlife experts.

\section{Materials and Methods}

The present study was conducted on the right and left scapulae of an adult male barking deer. The bones were processed as per standard technique (Raghavan, 1964) and subsequently studied to record gross morphological and biometrical features. Different biometrical parameters were measured with the help of thread, meter scale and Vernier Calipers as follows:

Maximum length $(\mathrm{cm})$ : Along the scapular spine

Diagonal length $(\mathrm{cm})$ : From coracoid process to caudal angle of scapula

Width of scapula $(\mathrm{cm})$ at three levels i.e. dorsal, middle and distal

Length of scapular spine (cm)

Height of scapular spine $(\mathrm{cm})$ at three levels i.e. dorsal, middle and proacromion level

Length $(\mathrm{cm})$ and height $(\mathrm{cm})$ of the acromion process

Antero-posterior and transverse diameters (cm) of glenoid cavity

Circumference of glenoid cavity $(\mathrm{cm})$

Maximum width $(\mathrm{cm})$ of supra-spinous and infra-spinous fossae

Scapular index (SI). It was calculated as the ratio between maximum length and maximum width of scapula (Bharti and Singh, 2017)

$\mathrm{SI}=($ Maximum length/Maximum width $) *$ 100

\section{Results and Discussion}

The scapula was flat, typically triangular in outline (Fig. 1). It was wider at dorsal end and narrower at ventral end which was similar to the findings of Raghavan, (1964) in ox, Getty, (1975) in horse, Choudhary et al., (2013) in chital, Choudhary, (2015) in Indian blackbuck and Bharti and Singh, (2017) and Rohlan et al., (2017) in Bluebull. The scapula presented two surfaces, three angles and three borders.

Medial surface presented deeper sub-scapular fossa (Fig. 2) as reported by Getty, (1975) in horse, Siddiqui et al., (2008) in Black Bengal goat and Choudhary and Singh, (2016) in Indian Black Buck. A distinct foramen was seen on this surface at distal $3^{\text {rd }}$ (Fig. 4).

The lateral surface was divided by a prominent scapular spine (Fig. 1) into a smaller supra-spinous fossa and a much larger infra-spinous fossa. Similar observations were noticed by Raghavan, (1964) in ox, Getty, (1975) in horse, Choudhary et al., (2013) in chital, Choudhary, (2015) in Indian blackbuck, Bharti and Singh, (2017) and Rohlan et al., (2017) in Bluebull. In contrast to this, Lahunta, (2013) in dog observed that these two fossae were almost equal.

The scapular spine was well developed and convex in outline (Fig. 6). It extended upto the neck of the bone and terminates as a pointed acromion process. In the middle of the spine was present a well-developed tuber spine (Fig. 1). In the distal half of the scapula, spine blends with the anterior border of the scapula.

Three borders were dorsal/vertebral, cranial and caudal. The caudal border was the thickest of all the borders which is also reported by Choudhary and Singh, (2016) in Indian Blackbuck and Sarma et al., (2017) in civet cat. 


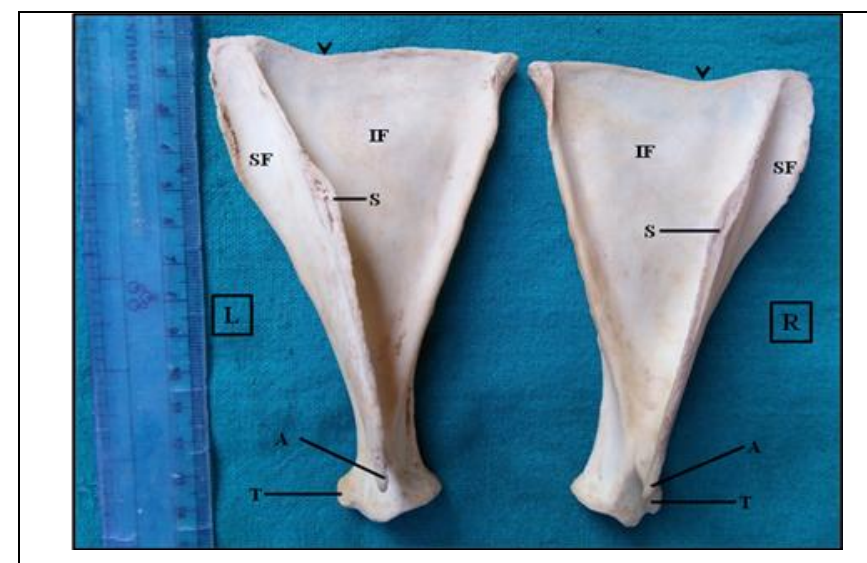

Fig.1 Lateral surface of right (R) and left (L) scapulae of barking deer showing supra-spinous fossa (SF), infra-spinous fossa (IF), tuber spine (S), notched dorsal border (arrow head), acromion process (A), tuber scapulae (T)

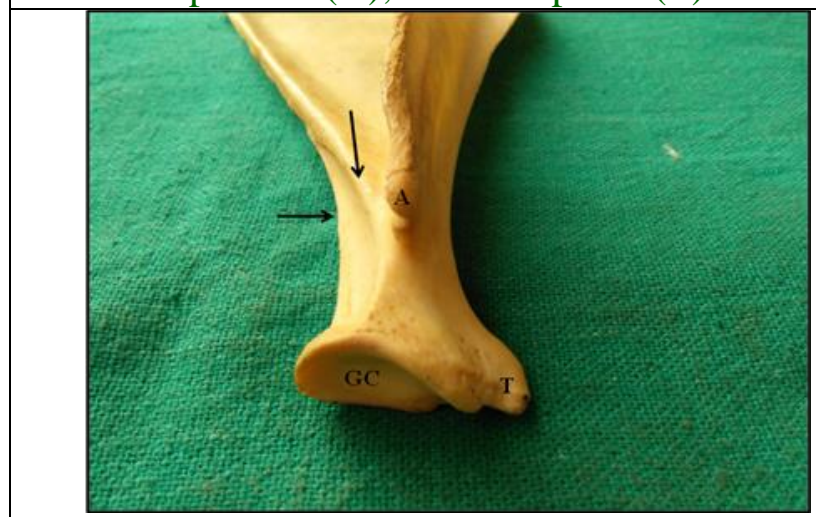

Fig.3 Distal extremity of scapula (lateral view) showing acromion process (A), tuber scapulae (T), glenoid cavity (GC) and posterior border showing two distinct ridges (arrow)

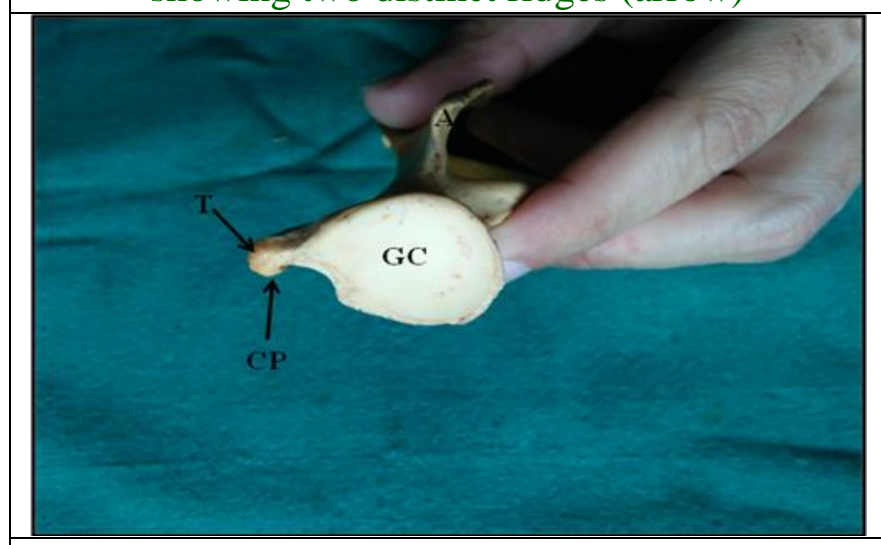

Fig.5 Ventral angle of scapula showing acromion process (A), tuber scapulae (T), glenoid cavity (GC), coracoid process (CP)

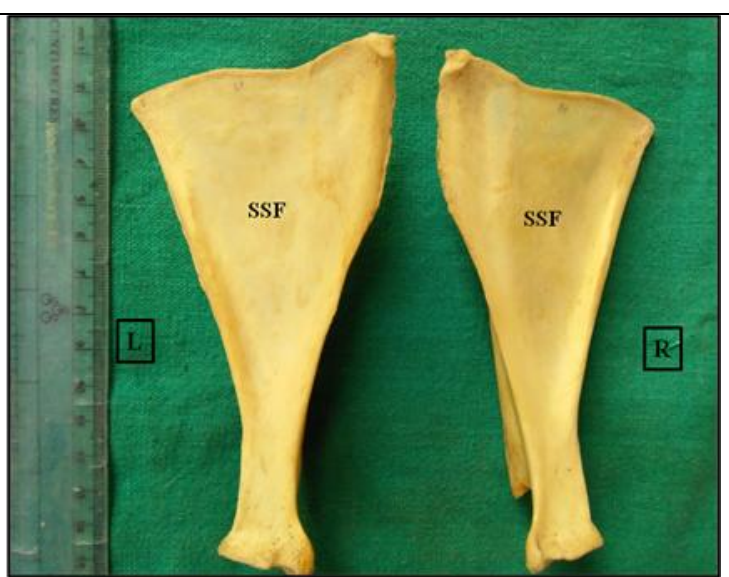

Fig.2 Medial surface of right (R) and left (L) scapulae of barking deer showing sub scapular fossa (SSF)

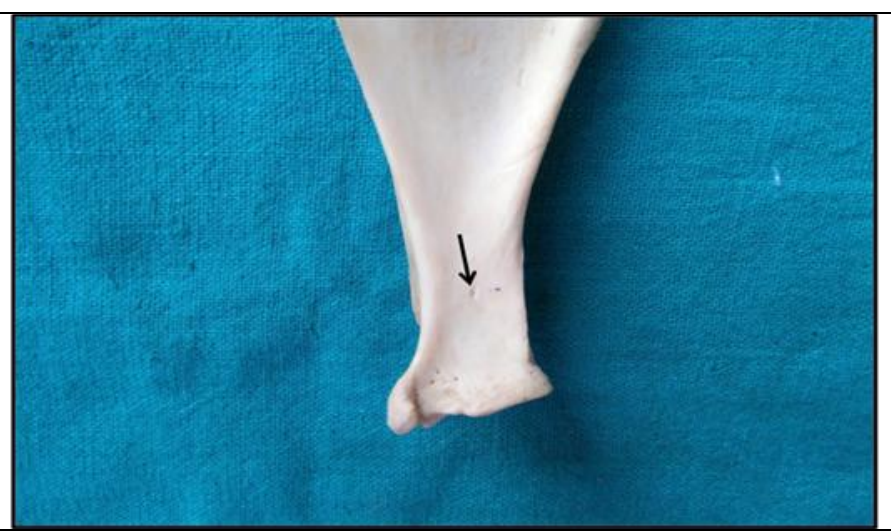

Fig.4 Distal extremity of scapula (medial view) showing a distinct foramen (arrow)

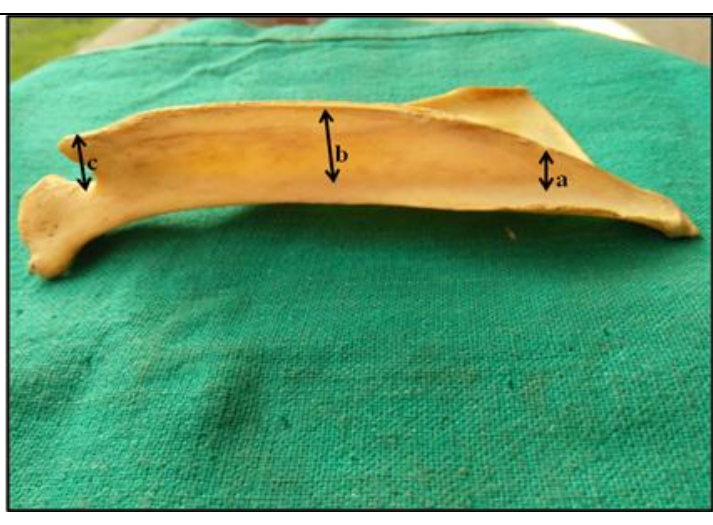

Fig.6 Lateral view of scapula showing height of scapular spine at different levels: dorsal (a), middle (b) and distal (c) 
Table.1 Biometry of scapula of adult Barking deer

\begin{tabular}{|c|c|c|c|}
\hline S. No. & Parameters & Right side & Lefit side \\
\hline 1. & Maximum length & $14 \mathrm{~cm}$ & $13.9 \mathrm{~cm}$ \\
\hline 2. & Diagonal length & $13.8 \mathrm{~cm}$ & $13.8 \mathrm{~cm}$ \\
\hline 3. & $\begin{array}{l}\text { Width of scapula } \\
\text { a. } \quad \text { Dorsal } \\
\text { b. } \quad \text { Middle } \\
\text { c. } \quad \text { Distal }\end{array}$ & $\begin{array}{l}7.61 \mathrm{~cm} \\
5.31 \mathrm{~cm} \\
1.54 \mathrm{~cm}\end{array}$ & $\begin{array}{l}7.73 \mathrm{~cm} \\
5.18 \mathrm{~cm} \\
1.57 \mathrm{~cm}\end{array}$ \\
\hline 4. & Length of scapular spine & $12.41 \mathrm{~cm}$ & $12.24 \mathrm{~cm}$ \\
\hline 5. & $\begin{array}{l}\text { Height of scapular spine } \\
\text { a. } \quad \text { Dorsal } \\
\text { b. } \quad \text { Middle } \\
\text { c. }\end{array}$ & $\begin{array}{l}0.8 \mathrm{~cm} \\
1.4 \mathrm{~cm} \\
1.3 \mathrm{~cm}\end{array}$ & $\begin{array}{l}1.0 \mathrm{~cm} \\
1.7 \mathrm{~cm} \\
1.5 \mathrm{~cm}\end{array}$ \\
\hline 6. & Length of acromion process & $0.6 \mathrm{~cm}$ & $0.6 \mathrm{~cm}$ \\
\hline 7. & Height of acromion process & $1.2 \mathrm{~cm}$ & $1.2 \mathrm{~cm}$ \\
\hline 8. & Circumference of glenoid cavity & $6.1 \mathrm{~cm}$ & $6.4 \mathrm{~cm}$ \\
\hline 9. & Antero-posterior diameter of glenoid cavity & $1.93 \mathrm{~cm}$ & $2.11 \mathrm{~cm}$ \\
\hline 10. & Transverse diameter of glenoid cavity & $1.73 \mathrm{~cm}$ & $1.82 \mathrm{~cm}$ \\
\hline 11. & Scapular index & 54.36 & 55.21 \\
\hline 12. & Maximum width of supra-spinous fossa & $1.3 \mathrm{~cm}$ & $1.25 \mathrm{~cm}$ \\
\hline 13. & Maximum width of infra-spinous fossa & $6.1 \mathrm{~cm}$ & $5.9 \mathrm{~cm}$ \\
\hline 14. & $\begin{array}{l}\text { Ratio of maximum width of supra-spinous to infra- } \\
\text { spinous fossa }\end{array}$ & $1: 4.69$ & $1: 4.72$ \\
\hline
\end{tabular}

Dorsal/vertebral border was thickest at both cranial and caudal ends and was notched towards cranial end (Fig. 1). The caudal border was much thicker than the cranial border. The outline of the caudal border in distal third was divided into two distinct ridges (Fig. 3). The lateral ridge meets postero-lateral part of the rim of the glenoid cavity whereas the other meets the posterior rim of glenoid cavity. Between these two ridges there was a distinct fossa.

Both cranial and caudal angles were well developed. The ventral angle presented the glenoid cavity which was cup-like and circular in outline (Fig. 5) as compared to shallow and circular in ox (Raghavan, 1964), oval in horse (Getty, 1975), circular and deep in Black Bengal goat (Siddique et al., 2008), shaped like heart of playing cards in Indian
Blackbuck (Choudhary and Singh, 2016), deep and circular in Blue bull (Bharti and Singh, 2017) and elliptically elongated in outline in civet cat (Sarma et al., 2017).

The tuber scapulae or supra-glenoid tubercle was small which was in accordance with the findings of Raghavan, (1964) in ox, Choudhary and Singh, (2016) in Indian Blackbuck and Bharti and Singh, (2017) in Bluebull; but it was in contrast to the findings of Getty, (1975) in horse. The coracoid process was well defined and projected as beak-like process (Fig. 5) medially from the anterior margin of the glenoid cavity. It was bent caudally. A small glenoid notch was present on the rim of the glenoid cavity.

The biometrical values of right and left scapulae of adult barking deer have been 
presented in Table 1. The maximum length of scapula along the spine (without scapular cartilage) was $14 \mathrm{~cm}$ for right scapula and $13.9 \mathrm{~cm}$ for the left one. The diagonal length was $13.8 \mathrm{~cm}$ for both scapulae. The width of scapula was measured at three levels. For right side, it was $7.61 \mathrm{~cm}$ at dorsal, $5.31 \mathrm{~cm}$ at middle and $1.54 \mathrm{~cm}$ at distal level. The decrease in width from dorsal to middle part was $30.22 \%$ whereas it was $71 \%$ from middle to distal part. The overall decrease in width from dorsal to distal part was $79.76 \%$. For left scapula, width was $7.73 \mathrm{~cm}, 5.18 \mathrm{~cm}$ and $1.57 \mathrm{~cm}$ at dorsal, middle and distal parts, respectively. The overall decrease in width from dorsal to distal part was $79.69 \%$. The decrease was $32.99 \%$ from dorsal to middle part and $69.69 \%$ from middle to distal part.

The scapular index was 54.36 and 55.21 for right and left scapulae, respectively. The same was 56.60 for blue bull (Bharti and Singh, 2017), 65.83 for sheep, 62.43 for buffalo, 57.51 for deer, 52.59 for ox, 45.45 for Nilgai and 43.62 for goat as recorded by Dalvi et al., (1997).

The total length of scapular spine was 12.41 $\mathrm{cm}$ and $12.24 \mathrm{~cm}$ for right and left scapulae, respectively. The height of scapular spine was measured at three levels. For right scapula, it was 0.8 at dorsal, $1.4 \mathrm{~cm}$ at middle and 1.3 $\mathrm{cm}$ at the level of acromion process. The same was $1 \mathrm{~cm}, 1.7 \mathrm{~cm}$ and $1.5 \mathrm{~cm}$ for left scapula. The spine thus showed an increase in height till middle (75\% for right scapula and $70 \%$ for left scapula) followed by a slight decrease (7.14\% for right scapula and $11.76 \%$ for left scapula). The ratio of length of scapular spine to its maximum height was 8.86 for right and 7.2 for left scapula. The length of acromion process $(0.6 \mathrm{~cm})$ and its height $(1.2 \mathrm{~cm})$ was same for both right and left scapulae.

For right scapula, the maximum width of supra-spinous fossa was $1.3 \mathrm{~cm}$ and infra- spinous fossa was $6.1 \mathrm{~cm}$. The ratio was 1 : 4.69. For left scapula, the maximum width of supra-spinous fossa was $1.25 \mathrm{~cm}$ and infraspinous fossa was $5.9 \mathrm{~cm}$. The ratio was 1: 4.72. It was 1: 2.97 in blue bull (Bharti and Singh, 2017), 1: 4.15 in chital (Choudhary et al., 2013) and 1: 3.21 in black buck (Choudhary, 2015).

The glenoid cavity had a circumference of 6.1 $\mathrm{cm}$ and $6.4 \mathrm{~cm}$ for right and left scapulae. For right bone, the antero-posterior diameter was $1.93 \mathrm{~cm}$ and transverse diameter was $1.73 \mathrm{~cm}$. The same was $2.11 \mathrm{~cm}$ and $1.82 \mathrm{~cm}$ for left scapula.

\section{References}

Bharti, S.K. and Singh, I. 2017. Gross and Morphometrical Studies on Scapula of Blue bull (Boselephus tragocamelus), Int. J. Pure and App. Bio. 5(3): 623627.

Choudhary, O.P and Singh, I. 2016. Morphometrical studies on scapula of Indian Blackbuck (Antelope cervicapra). Ind. Vet. J. 93 (01): 64-67.

Choudhary, O.P. 2015. Osteo-morphological studies of skull and appendicular skeleton of Indian Blackbuck (Antilope cervicapra). G.B.P.A.T. Pantnagar, India.

Choudhary, O.P., Mathur, R., Joshi, S., Beniwal, G. and Dangi, A. 2013. Gross and Biometrical studies on scapula of chital (Axis axis). Veterinary Practitioner 14(2): 224-227.

Dalvi, R.S., Bhamburkar, V.R., Ladukar, O.N. and Banubakode, S.B. 1997. Morphometric Study on Scapulae of Some Domestic and Wild Animals. Tech. Bul. XII Convention and National Symposium of IAVA, pp: 43.

Getty, R. 1975. Sisson and Grossman's The Anatomy of the Domestic Animals. $5^{\text {th }}$ edn. Volume I. WB Saunders Company, 
Philadelphia, USA, pp: 273-296.

Lahunta, E.D. 2013. Miller's Anatomy of the dog. $4^{\text {th }}$ edn. Elsevier Saunders, pp: 127-132.

Raghavan, D. 1964. Anatomy of ox. Indian Council of Agricultural Research, New Delhi, pp: 97-117.

Rohlan, K., Mathur, R. and Shringi, N. 2017. Morphometrical studies on scapula of Bluebull (Boselaphus tragocamelus). Journal of Wildlife Research 05(02): 16-19.

Sarma, K., Sasan, J.S. and Suri, S. 2017.
Gross and Morphometrical Studies on Scapula of Civet Cat (Viverricula indica). Int. J. Pure and App. Bio. 5(6): 80-85. doi: http://dx.doi.org/10.18782/23207051.5370

Siddiqui, M.S.I., M.Z.I. Khan, M. Sarma, M.N. Islam and M.R. Jahan (2008). Macro-anatomy of the bones of the limb of Black Bengal Goat (Capra hircus). Bangladesh Journal of Veterinary Medicine 6(1): 59-66.

\section{How to cite this article:}

Jasvinder Singh Sasan, Kamal Sarma and Shalini Suri. 2018. Gross and Morphometrical Studies on Scapula of Barking Deer (Muntiacus muntjak). Int.J.Curr.Microbiol.App.Sci. 7(02): 2820-2825. doi: https://doi.org/10.20546/ijcmas.2018.702.343 